\title{
Evaluation of Exposures and Symptoms from Heat Sealing Operations at a Plastic Film Assembly Facility
}

James Couch PhD, CIH, CSP, REHS/RS Judith Eisenberg, MD, MS

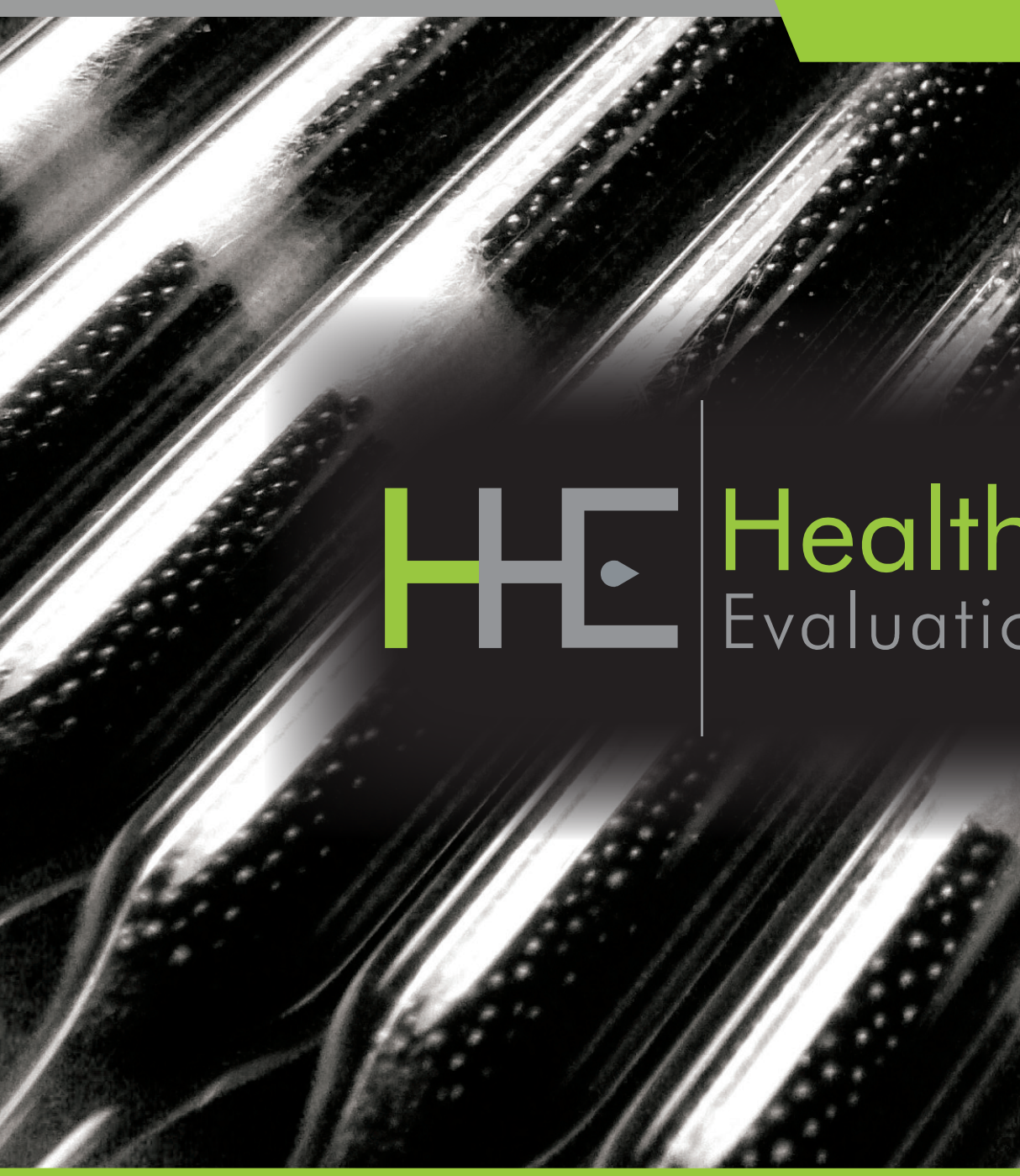

HHE Report No. 2014-0111-3280 May 2017

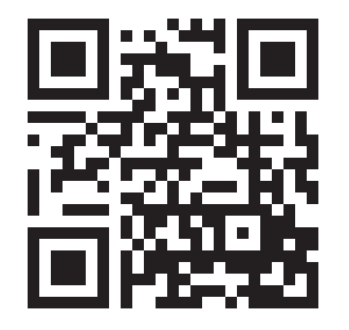

U.S. Department of Health and Human Services Centers for Disease Control and Prevention National Institute for Occupational Safety and Health
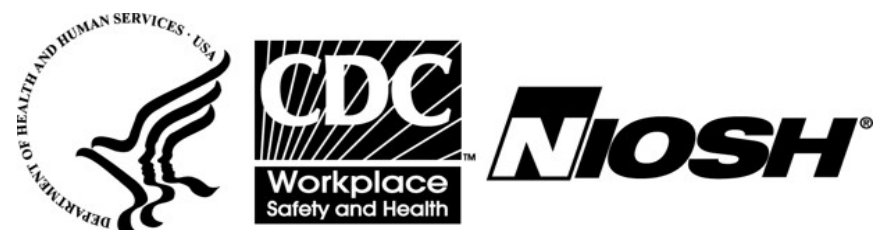


\section{Contents}

Highlights.

Abbreviations ...................................... iii

Introduction ............................................ 1

Methods ............................................. 2

Results ................................................ 4

Discussion ......................................... 10

Conclusions ...................................... 11

Recommendations.......................... 12

Appendix A ....................................... 14

Appendix B ......................................... 17

References ......................................... 19

Acknowledgements......................... 23

The employer is required to post a copy of this report for 30 days at or near the workplace(s) of affected employees. The employer must take steps to ensure that the posted report is not altered, defaced, or covered by other material.

The cover photo is a close-up image of sorbent tubes, which are used by the HHE Program to measure airborne exposures. This photo is an artistic representation that may not be related to this Health Hazard Evaluation. Photo by NIOSH. 


\section{Highlights of this Evaluation}

The Health Hazard Evaluation Program received a confidential employee request from a plastics and engineered film assembly facility. Employees were concerned about asthma, shortness of breath, heaviness in lungs, headaches, and overall health issues associated with high heat plastic sealing operations. We visited the facility in September 2014 and again in December 2015 after changes were made to operations.

\section{What We Did}

- We observed heat sealing work practices and toured the facility.

- We took air samples for dimethyl and diethyl phthalates, volatile organic compounds, carbon monoxide, and hydrogen chloride.

- We interviewed employees about their work and their health concerns.

\section{What We Found}

- We did not detect dimethyl phthalate or hydrogen chloride in any air sample.

- During our first visit, we identified diethyl phthalate in one volatile organic compound screening air sample taken on the Line $\mathrm{C}$ heat sealer. The level was too low to measure.

- The primary volatile organic compounds identified in the air at low levels were 2,5-diphenyl-p-benzoquinone, benzaldehyde, acetaldehyde, and formaldehyde.

- Spot measurements for carbon monoxide throughout the North building when forklifts were operating ranged from 55-67 parts per million in the morning and from 28-41 parts per million in the afternoon.

- Compared to the September 2014 site visit, on the December 2015 site visit we found:

We evaluated the high heat plastic sealing operations at a plastic film assembly facility before and after the company changed source materials. Employees' symptoms improved after the change in source materials, but some continued to experience headaches and asthma-like symptoms. Although we could not definitively link employee symptoms to a single exposure, we did find low levels of airborne chemicals, including diethyl phthalate and other volatile organic compounds, which could cause or worsen some symptoms. We did not detect hydrogen chloride or dimethyl phthalate in our air samples. Spot measurements showed the presence of carbon monoxide in areas where forklifts were used.

$\circ$ Fewer heat sealer employees reporting headache.

- Fewer heat sealer employees reporting asthma-like symptoms.

\section{What the Employer Can Do}

- Make sure forklifts are properly maintained and tuned to help minimize CO emissions.

- Do full-shift carbon monoxide exposure monitoring on employees in the North and 
South buildings, including forklift operators and employees working around forklifts. Train employees to recognize and report symptoms of carbon monoxide exposure.

\section{What Employees Can Do}

- Report work-related symptoms when they occur during heat sealing operations to your supervisors.

- If you have symptoms of asthma (shortness of breath, wheezing, difficulty breathing) see an occupational medicine physician for evaluation.

- Know the signs and symptoms of carbon monoxide exposures.

- If you experience symptoms of carbon monoxide exposure, alert your supervisor and seek medical attention promptly. 


\section{Abbreviations}

$\begin{array}{ll}\mu \mathrm{g} / \mathrm{m}^{3} & \text { Micrograms per cubic meter } \\ \text { ACGIH® } & \text { American Conference of Governmental Industrial Hygienists } \\ \text { CFR } & \text { Code of Federal Regulations } \\ \mathrm{CO} & \text { Carbon monoxide } \\ \mathrm{HCl} & \text { Hydrogen chloride } \\ \mathrm{m}^{3} & \text { Cubic meter } \\ \text { MDC } & \text { Minimum detectable concentration } \\ \text { NIOSH } & \text { National Institute for Occupational Safety and Health } \\ \text { OEL } & \text { Occupational exposure limit } \\ \text { OSHA } & \text { Occupational Safety and Health Administration } \\ \text { PEL } & \text { Permissible exposure limit } \\ \text { ppm } & \text { Parts per million } \\ \text { PVC } & \text { Polyvinyl chloride } \\ \text { REL } & \text { Recommended exposure limit } \\ \text { TLV }{ }^{\circ} & \text { Threshold limit value } \\ \text { TWA } & \text { Time-weighted average } \\ \text { VOC } & \text { Volatile organic compound }\end{array}$


This page left intentionally blank 


\section{Introduction}

The Health Hazard Evaluation Program received a request from employees at a plastic and engineered film manufacturing facility. The employees were concerned about headaches, asthma, and upper respiratory symptoms reported by employees that were potentially related to heat sealing operations. We initially visited the facility in September 2014. We visited again in December 2015 after the company changed owners and discontinued using the polyvinyl chloride (PVC) source product (blown film) in heat sealing operations that employees most associated with health complaints. The change was made because the blown film material did not meet the new company's quality standards. The second visit included the new South building, which was under construction during our first visit. We provided initial recommendations to employer and employee representatives in October 2014 and December 2015.

\section{Process Description}

The company produced large engineered sheeting, covers, and film liners for use in agricultural, construction, and industrial applications. The facility included a North and South Building, which both had heat sealing lines. The company had 41 employees at the time of our second site visit. The North building contained the three main heat sealing lines (Line A, Line B, and Line C) along with a stationary sealer, radiofrequency sealer, tarp machine (for adhesive bonding), sewing station (for grommet addition and repairs), maintenance shop, and administrative offices. The South building contained heat sealing Lines D and E along with administrative offices and a shipping department.

The number of heat sealing line employees decreased from 54 during our first site visit to 36 during our second site visit. Each heat sealing line required multiple employees, but not all heat sealing lines ran at the same time. Heat sealing employees routinely moved between production lines during the shift. The heat sealing process was similar for all five lines, and differed mainly by the size and composition of the source materials. Heat sealing employees were required to wear safety-toe shoes and hearing protection.

Employees verified the product specifications and brought the necessary feed materials to the line by hand or using propane-powered forklifts, a potential source of carbon monoxide (CO). CO can be generated from the incomplete combustion of any fossil fuel, including propane. These forklifts were also used to transport feed material between buildings.

Feed material consisted of plastic with various compositions, thicknesses, and lengths. To seal a seam, the feed material edges were aligned on top of one another and passed under a hot air knife with variable temperatures up to 1,200 degrees Fahrenheit, depending on the feed material. At the time of our first visit, blown film, a plastic material containing PVC, was the primary feed material of concern. When heated to high temperatures, it can release potentially toxic gases and vapors (volatile organic compounds [VOCs]). These may include plasticizers and hydrogen chloride $(\mathrm{HCl})$ [NLM 2015b]. The safety data sheets did not list specific plasticizers and the company was not aware of which plasticizers were in the products. Exposure to excessive levels of gases and vapors released during high heat processes can cause health effects similar to those reported by employees. 


\section{Methods}

Our objectives were to:

- Evaluate potential occupational exposures to common phthalate plasticizers, $\mathrm{HCl}$, $\mathrm{CO}$, and VOCs

- Identify possible health problems associated with heat sealing operations

Our evaluation included the following:

1. Review of an Occupational Safety and Health Administration (OSHA) complaint, environmental consultant reports, OSHA's Form 300 Log of Work-Related Injuries and Illnesses, and safety data sheets for feed materials

2. Collection of air samples for diethyl and dimethyl phthalates, $\mathrm{HCl}, \mathrm{CO}$, and VOCs

3. Confidential interviews with employees during both site visits

4. Collection of post-shift symptom surveys during the second site visit

\section{Document Review}

We reviewed the report from an OSHA investigation closed on April 14, 2014. We also reviewed two consultants' reports from exposure assessments conducted in March and July 2014. We reviewed the OSHA Logs for 2009-2012 and 2014-2015. OSHA Logs for 2013 were not available.

\section{Environmental Sampling}

In the evaluation request, blown film was identified as the product most associated with health symptoms and complaints. Because the new owner stopped using the blown film and changed to another PVC feed material after our first visit, our sampling plan for the second visit was different from the first.

\section{Volatile Organic Compounds}

During both visits, we took area air samples on the first shift using thermal tubes to qualitatively identify the presence of VOCs. During our first visit we took eight thermal desorption tube air samples for VOCs in the North building. During our second visit we took six thermal desorption tube air samples in the North Building (Line A, Line C, and stationary) and three in the South Building (Line E). All thermal desorption tubes were collected and analyzed using National Institute for Occupational Safety and Health (NIOSH) Method 2549 [NIOSH 2017].

\section{Dimethyl and Diethyl Phthalates}

Two common plasticizers are dimethyl phthalate [NLM 2015a] and diethyl phthalate [NLM 2010]. During our first visit, we took four area air samples for dimethyl phthalate and diethyl phthalate in the radiofrequency sealer area because we thought this operation had the highest potential of producing airborne phthalates, if present in the product. We took air samples only 
in the afternoon because the sealer was not operating in the morning.

During our second visit, we took seven personal air samples in the North building for dimethyl phthalate and diethyl phthalate on employees at Line A $(n=2)$, Line C $(n=2)$, stationary $(\mathrm{n}=2)$, and sewing $(\mathrm{n}=1)$. In the South building, we took two personal air samples for dimethyl phthalate and diethyl phthalate on employees at Line D. All samples specifically looking for dimethyl and diethyl phthalate were collected and analyzed using OSHA Method 104 [OSHA 2017].

\section{Hydrochloric Acid}

We did not sample for $\mathrm{HCl}$ during the first visit. During our second visit, we took 15 personal air samples and four area samples for $\mathrm{HCl}$. We took the personal air samples in the North building (Line A $[n=4]$, Line $C[n=2]$, stationary $[n=2]$, and sewing $[n=3]$ ) and South building (Line $\mathrm{D}[\mathrm{n}=4]$ ) during first shift. We took area samples for $\mathrm{HCl}$ in the North building near Line A and Line $\mathrm{C}$, an administrative office, and the breakroom. All $\mathrm{HCl}$ samples were collected and analyzed using NIOSH Method 7907 [NIOSH 2017].

\section{Carbon Monoxide}

We did not sample for CO during the first visit. During the second visit, we took spot measurements for $\mathrm{CO}$ throughout the North building during the morning and again in the afternoon of the same day at approximately the same locations as the morning measurements. All CO measurements were made using a calibrated TSI ${ }^{\circledR}$ Q-Trak Indoor Air Quality Monitor, model 7575.

\section{Confidential Medical Interviews}

We interviewed employees during both site visits. During these confidential medical interviews, we asked about work history and health symptoms. We asked a set of four validated asthma screening questions because exposure to respiratory irritants can sometimes cause asthma-like symptoms [Grassi et al. 2003]. We evaluated work-relatedness for possible occupational asthma by asking each employee who answered "yes" to any of the asthma screening questions if each symptom improved during days off from work or on vacation. On both site visits we also asked about other symptoms such as dry or irritated eyes or sore or dry throat, which could result from exposure to a chemical irritant. We also asked participants if they had any medical conditions they felt were work-related.

During the first site visit, we invited all 28 employees working heat sealer stations on first and second shifts to participate in confidential medical interviews. During the second site visit, we invited all 38 employees working first and second shifts in all departments to participate. These included office, shipping department, and maintenance employees in addition to the heat sealing employees. We compared the prevalence of reporting one or more symptoms among heat sealing employees between our first and second visits using the chisquared or Fisher's exact tests. All statistical tests were two-tailed, and a $P$ value of less than 0.05 was considered significant. 


\section{Post-shift Symptom Surveys}

On the second visit, we conducted post-shift symptom surveys at the end of the first and second work shifts. The survey asked participants to identify their work shift, all work areas in both buildings that the employee worked during that shift, and symptoms that started during that work shift.

\section{Results}

\section{Document Review}

In March 2014, OSHA notified the company that they had received a complaint from an employee concerned that respiratory tract irritation was related to inadequate ventilation of smoke generated during heat sealing operations. In response, the company purchased new ventilation equipment, but it was not installed prior to our first visit. The new equipment reportedly consisted of one Dayton fume and smoke exhauster and an Airflow Systems,

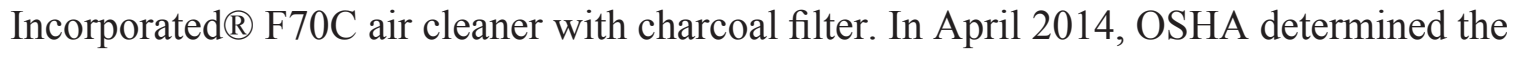
company's response was adequate and closed the case. During the second visit, we observed that the ventilation equipment had still not been installed. The new owner stated that they were unaware of any planned ventilation equipment installation at the time of purchase and could not locate the ventilation equipment.

The company hired a consultant to evaluate workplace exposures in April 2014 and another consultant to evaluate the workplace in July 2014. The April 2014 evaluation included personal air samples for formic acid, acetaldehyde, formaldehyde, acrolein, and respirable dust (particles not otherwise regulated). No result exceeded the lowest relevant occupational exposure limit (OEL) except formaldehyde, which was above the NIOSH recommended exposure limit (REL) of 0.016 parts per million ( $\mathrm{ppm}$ ), but below the OSHA permissible exposure limit (PEL) of $0.75 \mathrm{ppm}$ for an 8-hour time-weighted average (TWA) [NIOSH 2010; OSHA 2017]. The three full-shift formaldehyde measurements were $0.03,0.03$, and $0.04 \mathrm{ppm}$. The report concluded that the general ventilation system was insufficient and should be supplemented with local exhaust ventilation at the point of contaminant generation (e.g., heat sealing lines).

The July 2014 evaluation included area air sampling for formaldehyde, acrolein, phosgene, $\mathrm{HCl}, \mathrm{CO}$, and carbon dioxide. No detectable concentrations of $\mathrm{HCl}$, acrolein, or phosgene were found. However, two area air samples located on the heat sealer machine and in an area near the heat sealer $(0.028 \mathrm{ppm}$ and $0.027 \mathrm{ppm})$ were above the NIOSH REL, but below the OSHA PEL and OSHA action level for formaldehyde. These results were similar to those found by the other consultant in April 2014. A real time monitor was placed near a heat sealer and recorded an average $\mathrm{CO}$ concentration of $6 \mathrm{ppm}$ with a maximum concentration of $9 \mathrm{ppm}$. The NIOSH ceiling limit for $\mathrm{CO}$ is $200 \mathrm{ppm}$. The ceiling limit should not be exceeded at any time during the work shift. NIOSH also has a REL for CO of 35 ppm, as an 8-hour TWA [NIOSH 2010]. The average carbon dioxide concentration was $495 \mathrm{ppm}$ with a maximum concentration of 798 ppm. The air monitor ran for 132 minutes and measured concentrations every 30 seconds. The consultant noted that multiple doors were open to the outdoors during the sampling period. 
We reviewed the company's OSHA Logs for years 2009-2012 and 2014-2015. All 16 reported incidents between 2009 and 2012 involved musculoskeletal injuries (strains, sprains, fractures, and lacerations). The OSHA Logs contained no documented reports of illnesses, such as asthma. Only one incident (a contusion) was reported in 2014, and all four reported incidents in 2015 were musculoskeletal (shoulder dislocation, head contusion, and two low back strains).

\section{Environmental Sampling}

\section{Volatile Organic Compounds}

During the first visit, the screening area air samples indicated the presence of diethyl phthalate on one sample (Line C), benzaldehyde on one sample (breakroom), and acetaldehyde on six samples including the field blank. The diethyl phthalate, benzaldehyde, and acetaldehyde were all identified as small chromatograph peaks indicating they were present in low concentrations. Of the three chemicals, only benzaldehyde was identified during our second visit (Line A and stationary).

Four of the nine VOC area samples taken on our second visit indicated the presence of 2,5-diphenyl-p-benzoquinone, a polymerization inhibitor. These four samples were collected in the North building at the stationary sealer (two samples) and on heat sealers at Line A (one sample) and Line $\mathrm{C}$ (one sample). This compound was not present in VOC samples on the first visit. Formaldehyde was identified on two samples (Line E and tarping machine) as well as in the field blank. Formaldehyde was not identified during the first visit. The VOCs identified most frequently and with the largest peaks were toluene, cyclohexane, propane, and limonene. Toluene and cyclohexane are commonly found in industrial solvents. Limonene is a common ingredient in cleaners.

\section{Dimethyl and Diethyl Phthalates}

We detected no dimethyl phthalate or diethyl phthalate in any of the four area air samples taken during our first visit. The minimum detectable concentration (MDC) of both phthalates was 4.2 micrograms per cubic meter $\left(\mu \mathrm{g} / \mathrm{m}^{3}\right)$. This indicates that the diethyl phthalate identified in one of the screening samples was present in very low concentrations, below those we could detect with our quantitative methods. Appendix B, Table B1 has more detailed sample information.

We detected no dimethyl phthalate or diethyl phthalate in any of the nine personal samples taken during our second visit. The MDCs were $2.0 \mu \mathrm{g} / \mathrm{m}^{3}$ for dimethyl phthalate and $2.7 \mu \mathrm{g} / \mathrm{m}^{3}$ for diethyl phthalate. Appendix B, Table B2 has more detailed sample information.

\section{Hydrochloric Acid}

We detected no $\mathrm{HCl}$ in any of the personal samples taken on the second visit. The MDC for $\mathrm{HCl}$ was $2.7 \mu \mathrm{g} / \mathrm{m}^{3}$. We did not sample for $\mathrm{HCl}$ during our first visit. Appendix B, Table B3 has more detailed sample information. 


\section{Carbon Monoxide}

During our second visit, we took 12 spot measurements for CO throughout the North building during the morning of the first shift (Figure 1) and $10 \mathrm{CO}$ measurements in the same locations in the afternoon (Figure 2). Forklifts were operating in the North building at the time of our measurements. Our measurements included areas of heavy forklift use and areas where forklifts were not operating. CO concentrations ranged from 55-67 ppm in the morning and from 28-41 ppm in the afternoon. The highest $\mathrm{CO}$ levels were near Line $\mathrm{C}$, particularly near the radiofrequency sealer. The levels we measured were below the NIOSH ceiling level for CO of 200 ppm. We did not take CO measurements in the South building because it had only limited forklift traffic.

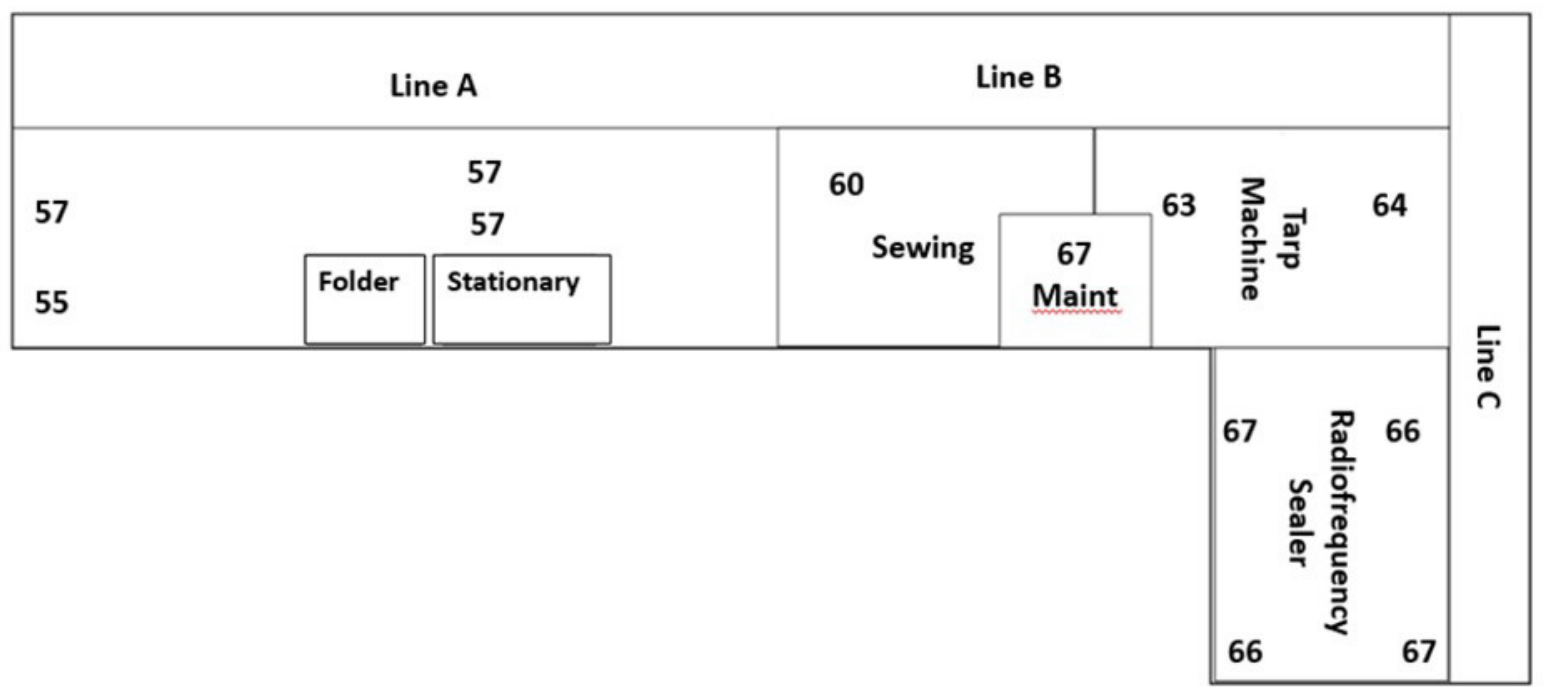

Figure 1. North building $\mathrm{CO}$ measurements (ppm) and location during the morning.

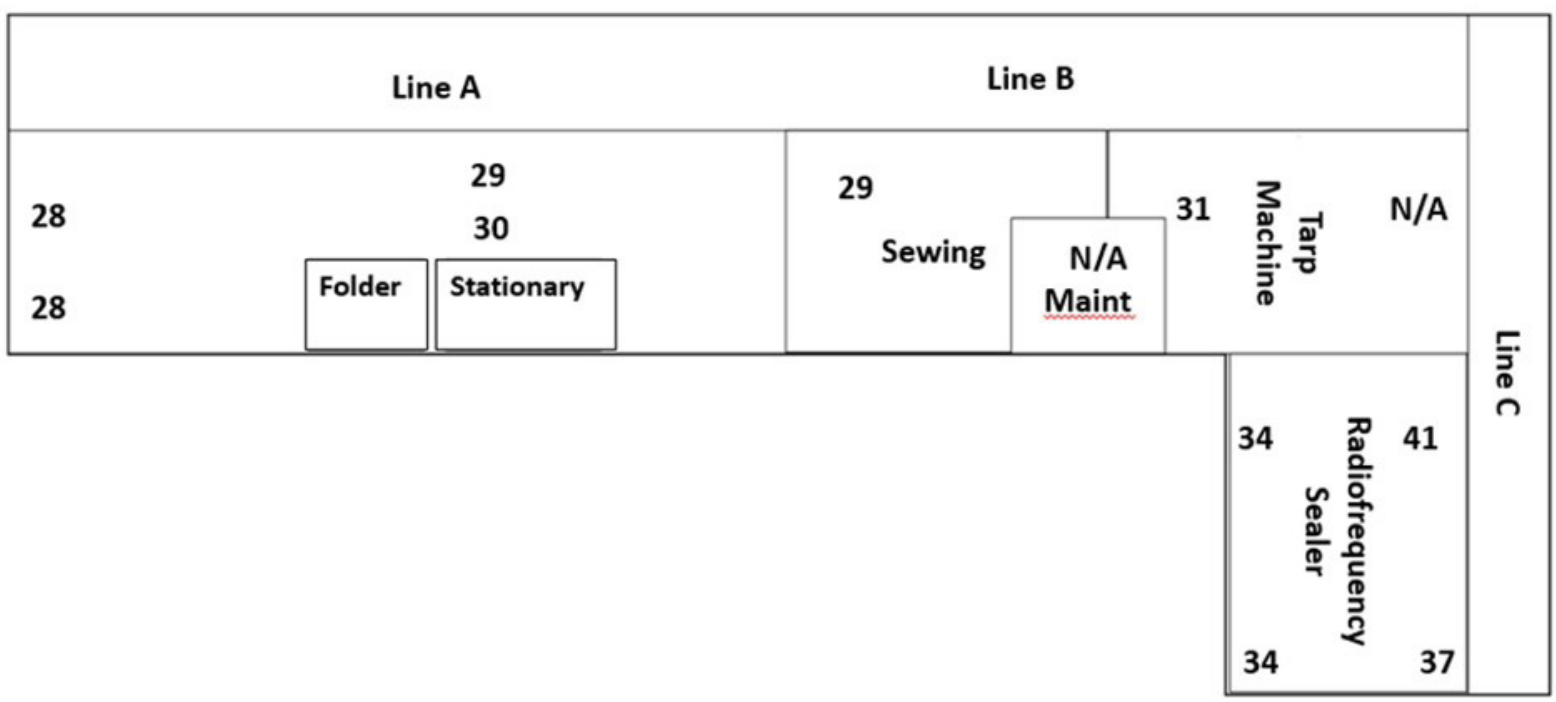

Figure 2. North building CO measurements (ppm) and location during the afternoon. 


\section{Confidential Medical Interviews}

During our first site visit, 25 (85\%) of 29 employees working the heat sealing stations participated in the confidential interviews, with 13 first shift employees and 12 second shift employees. During the second site visit, we interviewed all 38 employees working at the facility. Eleven of these employees participated in the interviews during the first site visit. Three other employees who participated in the first site visit were still working at the company at the time of the second site visit, but were on leave and did not participate in the second round of interviews. Of the 38 interviewed employees, 33 worked in heat sealing. Table 1 summarizes the demographic and work characteristics of interviewed employees.

Table 1. Demographics and work characteristics of interviewed employees

\begin{tabular}{|c|c|c|c|}
\hline & $\begin{array}{c}\text { September } 2014 \\
\text { heat sealing } \\
\text { employees only } \\
{[n=25]}\end{array}$ & $\begin{array}{l}\text { December } 2015 \\
\text { heat sealing } \\
\text { employees only } \\
{[n=33]}\end{array}$ & $\begin{array}{c}\text { December } 2015 \\
\text { non-heat sealing } \\
\text { employees only } \\
{[n=5]}\end{array}$ \\
\hline Median age (range in years) & $31(21-55)$ & $37(21-57)$ & $47(28-58)$ \\
\hline Number of males (\%) & $23(92)$ & $29(89)$ & $3(60)$ \\
\hline $\begin{array}{l}\text { Median employment duration in } \\
\text { heat sealing (range in years) }\end{array}$ & $0.8(0.01-11)$ & $1.5(0.3-21)$ & NA \\
\hline $\begin{array}{l}\text { Median years of facility } \\
\text { employment (range in years) }\end{array}$ & $6.5(0.5-8)$ & $2.0(0.3-23)$ & $4(2-9)$ \\
\hline \multicolumn{4}{|l|}{ NA $=$ Not applicable } \\
\hline
\end{tabular}

The HHE request mentioned non-specific symptoms, e.g., "shortness of breath and heaviness in lungs", that could occur because of exposure to chemical irritants or the development of work-related asthma. Therefore, we asked a panel of questions looking at possible irritant symptoms and then a separate set of work-related asthma screening questions. For the irritant symptoms, we asked employees about symptoms experienced in the past month that started during the work shift. On the first visit, headache (36\%) and dizziness (32\%) were the most commonly reported symptoms. Eighteen (72\%) employees reported one or more symptoms. On the second site visit, the most commonly reported symptom among heat sealers was cough (16\%); headache and dry or irritated eyes were the next most commonly reported symptoms (15\%). Eleven (33\%) heat sealing employees reported one or more symptoms. The percentage of heat sealing employees reporting one or more symptoms decreased significantly between the first and second visits $(72 \%$ vs. $33 \%, P<0.01)$. In addition, the percentage of heat sealing employees reporting headaches decreased between the first and second visits $(36 \%$ vs. $16 \%, P=0.048)$. Table 2 summarizes the symptoms experienced by interviewed employees in the month prior to each site visit. 
Table 2. Symptoms reported by interviewed employees in the past month

\begin{tabular}{lccc}
\hline $\begin{array}{l}\text { Symptom } \\
\text { reported }\end{array}$ & $\begin{array}{c}\text { September 2014 heat } \\
\text { sealers only }[\mathrm{n}=25] \\
\text { (\% within category) }\end{array}$ & $\begin{array}{c}\text { December 2015 heat } \\
\text { sealers only [n=33] } \\
(\% \text { within category) }\end{array}$ & $\begin{array}{c}\text { December 2015 non- } \\
\text { heat sealers only [n }=5] \\
\text { (\% within category) }\end{array}$ \\
\hline Any symptom & $18(72)$ & $11(33)$ & $2(40)$ \\
Headache & $9(36)$ & $5(15)$ & $1(20)$ \\
Dizziness & $8(32)$ & $1(3)$ & 0 \\
Cough & $7(28)$ & $6(18)$ & 0 \\
Dry or irritated eyes & $6(24)$ & $5(15)$ & 0 \\
Black mucus or & $5(20)$ & $3(9)$ & $1(20)$ \\
nasal discharge & & & 0 \\
Runny nose & $5(20)$ & $4(12)$ & 0 \\
Stuffy nose & $5(20)$ & $4(12)$ & 0 \\
Sore or dry throat & $5(20)$ & $3(9)$ & 0 \\
Shortness of breath & $4(16)$ & $1(3)$ & 0 \\
Nausea & $1(4)$ & 0 & \\
\hline
\end{tabular}

During the first site visit, six of 25 employees reported "yes" to one or more of the asthma screening questions. One of the six reported having a previous diagnosis of asthma. This employee did not note any improvement in symptoms when away from work. Two others also reported that their symptoms did not improve when away from work; the remaining three employees reported improvement of symptoms on days off from work. Therefore, three employees possibly had work-related asthma. The employee with the pre-existing asthma diagnosis was not one of these three. Four employees reported being current or former smokers.

During the second site visit, all seven of the employees who reported "yes" to one or more of the asthma screening questions worked in heat sealing areas. Three had previous diagnoses of asthma. None reported that their symptoms improved when away from work so we could not conclude that any of these seven employees had work-related asthma. Three employees reported being current or former smokers. In response to the question "Do you have any medical condition you feel is work-related?" asked at both site visits, none of the interviewed employees reported respiratory problems that they believed were work-related. There were only two employees present at both site visits who responded "yes" to one or more of the asthma screening questions. One employee's responses were the same for both visits with an answer to yes to only one of the four screening questions. The second employee answered yes to one screening question at the first site visit but had yes responses to two screening questions at the second site visit.

Only one of the three employees with possible work-related asthma from the first site visit were also present at the second site visit. Although this employee responded yes to the same screening question as they did on the first visit, they did not report symptom improvement when away from work during the second site visit as reported during the first site visit.

We also asked employees an open-ended question about any other work-related concerns. The focus of their responses was different between the visits. During the first site visit, 
employees reported concern about the lack of formal job training. Many felt that a more structured training program for new employees would be helpful instead of the existing informal apprenticeship approach. Other interviewed employees noted the unpleasant odor associated with the smoke generated from heat sealing products; specifically PVC and other blown film products. These odors were reported by employees who reported no irritant symptoms and/or headache. Heat sealing woven product was reported to generate a "shampoo" odor.

During the second site visit 29 (97\%) interviewed employees who worked in heat sealing areas reported improved ventilation and/or less smoke and associated odor. Other comments from interviewed employees were that the new management was more safety and health conscious (e.g., they held more frequent safety toolbox talks, seat belts were placed in the forklift). Employees also noted that that the plant was kept cleaner. They reported that this was likely due to a policy enacted by the new owner that set aside the last 30 minutes of each shift for employees to clean their work areas.

\section{Post-shift Symptom Surveys}

In total, 32 of 38 employees completed post-shift symptom surveys during the two days of the second site visit. The other six employees (all non-production) were on non-standard work schedules and were not available for the survey. The 32 employees who completed the post-shift symptom survey included 30 heat sealing employees and 2 employees working in other areas. Employees were asked about symptoms that began after they started work that day. Five $(16 \%)$ of the 32 employees reported one or more symptoms. Three employees had headaches; two heat sealers reported onset while working with PVC products; the third employee worked in the sewing area. There was one report of dizziness and one of nausea from different employees; both reported heat sealing with PVC product at the time of symptom onset. Two heat sealers reported shortness of breath while working in Line $\mathrm{C}$. One of these employees noted working with PVC products when the shortness of breath started, while the second employee could not relate symptom onset to a particular product. No employees reported onset of cough during the workday.

\section{General Observations}

During the first site visit, we observed a temporary welding operation to repair equipment. The welding operation was not shielded from employees working in adjacent areas, potentially exposing them to ultraviolet light and welding fumes. The welders wore welding helmets with protective eye shielding.

During the second site visit, we observed an employee dry sweeping the production floor to remove dirt tracked into the North building by forklifts coming from outdoors. Employees were directed by the employer to dry sweep before cleaning the floor using wet methods because of the excessive amounts of dirt on the floor and the potential to create muddy conditions. Dry sweeping increases airborne dust, which can reduce visibility and could be inhaled by employees as well as act as an irritant. 
During the first visit, ventilation systems were operating and multiple outside doors were open. A noticeable breeze was observed in several locations throughout the production floor. During our second visit, ventilation systems were operating but all doors were shut due to the cold outside temperatures.

\section{Discussion}

Our interviews conducted during the first site visit revealed three heat sealing employees with possible undiagnosed occupational asthma as defined by responding yes to one or more of the asthma screening questions and stating that the symptom(s) improved when away from work. None of the three had been evaluated by an occupational medicine provider for treatment or to determine work-relatedness.

Occupational asthma is asthma that is triggered by workplace exposures and causes chest tightness, wheezing, and shortness of breath. When treated early, occupational asthma may be reversible. Long-term exposure to asthma-causing substances may worsen symptoms. Treatment for occupational asthma is similar to treatment for other types of asthma, and it generally includes taking medications to reduce symptoms. But the important thing is to prevent lung damage by avoiding whatever workplace exposure is triggering the asthma. Employees diagnosed with occupational asthma that is confirmed to be associated with specific workplace exposures may need to be reassigned to work areas away from the causative agent.

Formaldehyde, which can be produced during the heat sealing process, has been associated with the development of occupational asthma. It can also act as a sensitizer and make those exposed more susceptible to occupational asthma [ATSDR 1999, 2015; Jaakkola and Knight 2008]. Formaldehyde was identified at low concentrations from VOC screening samples collected at Line E and the tarping machine. We reviewed sampling done by consultants in March 2014 and July 2014 that showed formaldehyde concentrations up to $0.04 \mathrm{ppm}$ that were above the NIOSH REL but below the OSHA action limit. It is possible that individuals sensitized to formaldehyde may experience asthma symptoms at these low levels [NIOSH 1991; Wallingford 2009]. Threshold exposure levels for irritant symptoms due to formaldehyde exposure as low as $0.003 \mathrm{ppm}$ have been reported [Salonen et al. 2009].

Symptoms can also result from exposure to substances that irritate the airways, including $\mathrm{HCl}$, phthalates, and some VOCs. Employees were asked about both irritant and asthmalike symptoms that were consistent with these exposures. During the first visit, employees reported headache and dizziness as the most common symptoms. Headaches and other symptoms caused by exposure to VOCs resolve quickly after being removed from the exposure [Palmer and Philips 2007].

We did not detect any $\mathrm{HCl}$ or dimethyl phthalate on any air sample. The VOC screening samples did identify the presence of diethyl phthalate, benzaldehyde, acetaldehyde, and formaldehyde. It is possible that exposure to these and other irritants, which could be produced during heat sealing operations, could be the source of the symptoms reported during both site visits even if they are present in low levels. A medical evaluation of affected 
employees by a physician well versed in occupational exposures and disease is needed to determine if the symptoms may be from exposure to an irritant, asthma, exacerbation of a pre-existing lung condition, or non-work exposures, like tobacco smoke.

Our findings demonstrated a statistically significant decrease in the percentage of employees reporting headache and one or more irritative symptoms at the second visit compared to the first. This decrease could be associated with a number of factors. During the second site visit, there were fewer reports of noxious odor and/or smoke produced during heat sealing and reports of improved ventilation in work areas. The new company reported no longer using the blown film product that some employees associated with smoke, odor, and symptoms during the first site visit. However, interviews conducted during the second site visit revealed that some employees were still associating symptom onset with the use of other PVC containing source products that had been substituted for the blown film product.

Employees used propane-powered forklifts, which produce carbon monoxide in the exhaust, to move feed materials to the production lines in both buildings. Our spot measurements showed that $\mathrm{CO}$ was present throughout the North building when forklifts were operating. During our measurements the windows and doors were closed due to the cold weather which, along with heavy forklift use, could explain the elevated spot $\mathrm{CO}$ measurement results. In colder weather, when doors and windows of the facility are closed, CO levels from forklift exhaust can rise quickly if the building's ventilation system does not supply adequate outdoor air for dilution. Our results showed that CO levels ranged 28-67 ppm, but we found that $\mathrm{CO}$ levels were about $25 \mathrm{ppm}$ lower during our afternoon measurements than during the morning measurements. This was most likely because more outdoor air was entering the building in the afternoon due to open doors while moving finished products and feed material between buildings. Because we took spot measurements, we cannot compare the CO results directly to full-shift OELs; however, if employees were exposed to these CO levels for a full shift, their exposures could exceed the ACGIH TLV of $25 \mathrm{ppm}$ or the NIOSH REL of $35 \mathrm{ppm}$. The previous owner did not have a propane-fueled vehicle maintenance program. However, the current owner stated that the propane-fueled forklifts were on a preventative maintenance program to help reduce $\mathrm{CO}$ emissions in forklift exhaust. $\mathrm{CO}$ exposure is often identified when a group of individuals at the same location simultaneously start to manifest symptoms of headache, nausea, or other flu-like symptoms (especially occurring without a fever) [Lavonias 2007; Maloney 2016]. CO exposure could contribute to some of the employee previous symptoms if $\mathrm{CO}$ levels had been elevated.

\section{Conclusions}

After the ownership change and the elimination of the blown film source material, fewer heat sealing employees reported headache and other irritant symptoms. Responses to our occupational asthma screening questions revealed three employees with possible workrelated asthma during the first site visit, who were urged to seek medical assessment. No cases of asthma were identified during the second visit. These findings may reflect the elimination of the blown film source material that many employees associated with improvements in overall plant hygiene. We identified the presence of the plasticizer, diethyl phthalate in very low concentrations on one VOC screening sample taken on the Line $\mathrm{C}$ heat 
sealer along with other VOCs (aldehydes) in several air samples that are irritants. Although these VOCs were present in concentrations well below OELs, the combination of VOCs could cause irritant symptoms in some employees. Spot CO measurements showed that employees can be exposed to $\mathrm{CO}$ in areas where propane-powered forklifts are used. Health symptoms such as headaches, previously reported by employees, can be caused by CO.

\section{Recommendations}

On the basis of our findings, we recommend the actions listed below. We encourage the facility to use an employee-management health and safety committee or working group to discuss our recommendations and develop an action plan. Those involved in the work can best set priorities and assess the feasibility of our recommendations for the specific situation at the facility.

Our recommendations are based on an approach known as the hierarchy of controls (Appendix A). This approach groups actions by their likely effectiveness in reducing or removing hazards. In most cases, the preferred approach is to eliminate hazardous materials or processes and install engineering controls to reduce exposure or shield employees. Until such controls are in place, or if they are not effective or feasible, administrative measures and personal protective equipment may be needed.

\section{Engineering Controls}

Engineering controls reduce employees' exposures by removing the hazard from the process or by placing a barrier between the hazard and the employee. Engineering controls protect employees effectively without placing primary responsibility of implementation on the employee.

1. If further $\mathrm{CO}$ monitoring shows that employees' exposures to $\mathrm{CO}$ are above full-shift or ceiling exposure limits, reduce $\mathrm{CO}$ exposures by implementing control measures such as increasing ventilation, installing catalytic converters on forklifts, or replacing propane-powered forklifts with electric forklifts.

2. Use welding screens, also known as welding curtains, for temporary welding operations to meet the requirements in the OSHA welding, cutting, and brazing standard, 29 CFR 1910.252.

\section{Administrative Controls}

The term administrative controls refers to employer-dictated work practices and policies to reduce or prevent hazardous exposures. Their effectiveness depends on employer commitment and employee acceptance. Regular monitoring and reinforcement are necessary to ensure that policies and procedures are followed consistently.

1. Select feed materials for the high heat plastic sealing operation that are the least likely to cause or generate chemical byproducts that cause respiratory irritation or are associated with the development of occupational asthma.

2. Measure employees', including forklift operators', full-shift and short-term CO 
exposures. Measurements should be made when forklifts are being used and the doors and windows to the outdoors are closed.

3. Make sure forklifts are properly maintained and tuned to help minimize CO emissions.

4. Train employees to recognize and report symptoms of $\mathrm{CO}$ exposure. For additional information refer to the OSHA CO fact sheet available at https://www.osha.gov/OshDoc/data_General Facts/carbonmonoxide-factsheet.pdf.

5. Refer employees reporting asthma-like symptoms to occupational medicine or lung specialists with expertise in occupational lung diseases.

6. Conduct refresher training on the health effects of heat-sealing by-products.

7. Create a new employee orientation guide that includes a standard operating procedure for the heat sealing process showing how to perform the work safely and answering frequently asked questions. The management-employee safety committee should have input into this document.

8. Use a HEPA-filtered vacuum cleaner to remove excess forklift dirt from the production floor instead of dry sweeping.

9. Install forklift truck mats at forklift entrances to reduce dirt tracked into the building. 


\section{Appendix A: Occupational Exposure Limits and Health Effects}

NIOSH investigators refer to mandatory (legally enforceable) and recommended OELs for chemical, physical, and biological agents when evaluating workplace hazards. OELs have been developed by federal agencies and safety and health organizations to prevent adverse health effects from workplace exposures. Generally, OELs suggest levels of exposure that most employees may be exposed to for up to 10 hours per day, 40 hours per week, for a working lifetime, without experiencing adverse health effects. However, not all employees will be protected if their exposures are maintained below these levels. Some may have adverse health effects because of individual susceptibility, a pre-existing medical condition, or a hypersensitivity (allergy). In addition, some hazardous substances act in combination with other exposures, with the general environment, or with medications or personal habits of the employee to produce adverse health effects. Most OELs address airborne exposures, but some substances can be absorbed directly through the skin and mucous membranes.

Most OELs are expressed as a TWA exposure. A TWA refers to the average exposure during a normal 8- to 10-hour workday. Some chemical substances and physical agents have recommended STEL or ceiling values. Unless otherwise noted, the STEL is a 15-minute TWA exposure. It should not be exceeded at any time during a workday. The ceiling limit should not be exceeded at any time.

In the United States, OELs have been established by federal agencies, professional organizations, state and local governments, and other entities. Some OELs are legally enforceable limits; others are recommendations.

- The U.S. Department of Labor OSHA PELs (29 CFR 1910 [general industry]; 29 CFR 1926 [construction industry]; and 29 CFR 1917 [maritime industry]) are legal limits. These limits are enforceable in workplaces covered under the Occupational Safety and Health Act of 1970.

- NIOSH RELs are recommendations based on a critical review of the scientific and technical information and the adequacy of methods to identify and control the hazard. NIOSH RELs are published in the NIOSH Pocket Guide to Chemical Hazards [NIOSH 2010]. NIOSH also recommends risk management practices (e.g., engineering controls, safe work practices, employee education/training, personal protective equipment, and exposure and medical monitoring) to minimize the risk of exposure and adverse health effects.

- Another set of OELs commonly used and cited in the United States is the ACGIH TLVs. The TLVs are developed by committee members of this professional organization from a review of the published, peer-reviewed literature. TLVs are not consensus standards. They are considered voluntary exposure guidelines for use by industrial hygienists and others trained in this discipline "to assist in the control of health hazards" [ACGIH 2017]. 
Outside the United States, OELs have been established by various agencies and organizations and include legal and recommended limits. The Institut für Arbeitsschutz der Deutschen Gesetzlichen Unfallversicherung (Institute for Occupational Safety and Health of the German Social Accident Insurance) maintains a database of international OELs from European Union member states, Canada (Québec), Japan, Switzerland, and the United States. The database, available at http://www.dguv.de/ifa/GESTIS/GESTIS-Internationale-Grenzwerte-fürchemische-Substanzen-limit-values-for-chemical-agents/index-2.jsp, contains international limits for more than 2,000 hazardous substances and is updated periodically.

OSHA requires an employer to furnish employees a place of employment free from recognized hazards that cause or are likely to cause death or serious physical harm [Occupational Safety and Health Act of 1970 (Public Law 91-596, sec. 5(a)(1))]. This is true in the absence of a specific OEL. It also is important to keep in mind that OELs may not reflect current health-based information.

When multiple OELs exist for a substance or agent, NIOSH investigators generally encourage employers to use the lowest OEL when making risk assessment and risk management decisions. NIOSH investigators also encourage use of the hierarchy of controls approach to eliminate or minimize workplace hazards. This includes, in order of preference, the use of (1) substitution or elimination of the hazardous agent, (2) engineering controls (e.g., local exhaust ventilation, process enclosure, dilution ventilation), (3) administrative controls (e.g., limiting time of exposure, employee training, work practice changes, medical surveillance), and (4) personal protective equipment (e.g., respiratory protection, gloves, eye protection, hearing protection). Control banding, a qualitative risk assessment and risk management tool, is a complementary approach to protecting employee health. Control banding focuses on how broad categories of risk should be managed. Information on control banding is available at http://www.cdc.gov/ niosh/topics/ctrlbanding/. This approach can be applied in situations where OELs have not been established or can be used to supplement existing OELs.

\section{Carbon Monoxide}

$\mathrm{CO}$ is a colorless, odorless, tasteless gas produced by incomplete burning of carboncontaining materials such as gasoline or propane fuel. The initial symptoms of $\mathrm{CO}$ poisoning may include headache, dizziness, drowsiness, or nausea. Symptoms may advance to vomiting, loss of consciousness, and collapse if prolonged or high exposures are encountered. If the exposure level is high, loss of consciousness may occur without other symptoms. Coma or death may occur if high exposures continue [Blumenthal 2001]. The display of symptoms varies widely from individual to individual, and may occur sooner in susceptible individuals such as young or aged people, people with preexisting lung or heart disease, or those living at high altitudes.

Exposure to $\mathrm{CO}$ limits the ability of the blood to carry oxygen to the tissues by binding with the hemoglobin to form carboxyhemoglobin. Once exposed, the body compensates for the reduced blood-borne oxygen by increasing cardiac output, thereby increasing blood flow to specific oxygen-demanding organs such as the brain and heart. This ability may be limited by 
pre-existing heart or lung diseases that inhibit increased cardiac output.

The NIOSH REL for CO is 35 ppm as a full-shift TWA exposure, with a ceiling limit of 200 ppm that should never be exceeded [NIOSH 2010]. NIOSH has established the immediately dangerous to life or health value for $\mathrm{CO}$ as $1,200 \mathrm{ppm}$ [NIOSH 2010]. This value is the concentration at which an immediate or delayed threat to life exists or that would interfere with an individual's ability to escape unaided from a space. ACGIH recommends an 8-hour TWA TLV of 25 ppm [ACGIH 2017]. ACGIH also recommends that exposures never exceed five times the TLV (thus, never to exceed 125 ppm) [ACGIH 2017]. The OSHA PEL for $\mathrm{CO}$ is $50 \mathrm{ppm}$ for an 8-hour TWA exposure [OSHA 2017]. 


\section{Appendix B: Tables}

Table B1. Concentrations of dimethyl phthalate and diethyl phthalate in work shift area air samples, September 25, 2014

\begin{tabular}{|c|c|c|c|}
\hline & $\begin{array}{c}\text { Sample duration } \\
\text { (minutes) }\end{array}$ & $\begin{array}{c}\text { Dimethyl phthalate } \\
\left(\mu \mathrm{g} / \mathrm{m}^{3}\right)^{*}\end{array}$ & $\begin{array}{c}\text { Diethyl phthalate } \\
\left(\mu \mathrm{g} / \mathrm{m}^{3}\right) \dagger\end{array}$ \\
\hline \multicolumn{4}{|c|}{ Radiofrequency sealer } \\
\hline Area 1 & 847 & ND & ND \\
\hline Area 2 & 748 & ND & ND \\
\hline Area 3 & 870 & ND & ND \\
\hline Area 4 & 747 & ND & ND \\
\hline
\end{tabular}

Table B2. Concentrations of dimethyl phthalate and diethyl phthalate in work shift personal air samples, December 9, 2015

\begin{tabular}{|c|c|c|c|}
\hline & $\begin{array}{c}\text { Sample duration } \\
\text { (minutes) }\end{array}$ & $\begin{array}{l}\text { Dimethyl phthalate } \\
\left(\mathrm{mg} / \mathrm{m}^{3}\right)^{\star}\end{array}$ & $\begin{array}{l}\text { Diethyl phthalate } \\
\left(\mathrm{mg} / \mathrm{m}^{3}\right) \dagger\end{array}$ \\
\hline \multicolumn{4}{|l|}{ Line A } \\
\hline Operator 1 & 306 & ND & ND \\
\hline Operator 2 & 229 & ND & ND \\
\hline \multicolumn{4}{|l|}{ Line C } \\
\hline Operator 1 & 290 & ND & ND \\
\hline Operator 2 & 263 & ND & ND \\
\hline \multicolumn{4}{|l|}{ Line D } \\
\hline Operator 1 & 475 & ND & ND \\
\hline Operator 2 & 270 & ND & ND \\
\hline \multicolumn{4}{|l|}{ Stationary } \\
\hline Operator 1 & 253 & ND & ND \\
\hline Operator 2 & 271 & ND & ND \\
\hline \multicolumn{4}{|l|}{ Sewing } \\
\hline Operator 1 & 187 & ND & ND \\
\hline NIOSH REL & - & $5 \mathrm{mg} / \mathrm{m}^{3}$ & $5 \mathrm{mg} / \mathrm{m}^{3}$ \\
\hline OSHA PEL & - & $5 \mathrm{mg} / \mathrm{m}^{3}$ & $5 \mathrm{mg} / \mathrm{m}^{3}$ \\
\hline ACGIH TLV & - & $5 \mathrm{mg} / \mathrm{m}^{3}$ & $5 \mathrm{mg} / \mathrm{m}^{3}$ \\
\hline
\end{tabular}

*The MDC of dimethyl phthalate was $2.0 \mu \mathrm{g} / \mathrm{m}^{3}$ using an average sample volume of $0.295 \mathrm{~m}^{3}$. †The MDC of diethyl phthalate was $2.7 \mu \mathrm{g} / \mathrm{m}^{3}$ using an average sample volume of $0.295 \mathrm{~m}^{3}$. 
Table B3. Concentrations of hydrochloric acid in work shift personal air samples, December 9, 2015

\begin{tabular}{|c|c|c|}
\hline & $\begin{array}{l}\text { Sample duration } \\
\text { (minutes) }\end{array}$ & $\begin{array}{l}\text { Hydrochloric acid } \\
\left(\mathrm{mg} / \mathrm{m}^{3}\right)^{*}\end{array}$ \\
\hline \multicolumn{3}{|l|}{ Line A } \\
\hline Operator 1 & 594 & ND \\
\hline Operator 2 & 588 & ND \\
\hline Operator 3 & 579 & ND \\
\hline Operator 4 & 593 & ND \\
\hline \multicolumn{3}{|l|}{ Line C } \\
\hline Operator 1 & 585 & ND \\
\hline Operator 2 & 570 & ND \\
\hline \multicolumn{3}{|l|}{ Line D } \\
\hline Operator 1 & 566 & ND \\
\hline Operator 2 & 559 & ND \\
\hline Operator 3 & 552 & ND \\
\hline Operator 4 & 553 & ND \\
\hline \multicolumn{3}{|l|}{ Stationary } \\
\hline Operator 1 & 554 & ND \\
\hline Operator 2 & 551 & ND \\
\hline \multicolumn{3}{|l|}{ Sewing } \\
\hline Operator 1 & 540 & ND \\
\hline Operator 2 & 536 & ND \\
\hline Operator 3 & 540 & ND \\
\hline NIOSH REL & - & Ceiling: $7 \mathrm{mg} / \mathrm{m}^{3}$ \\
\hline OSHA PEL & - & Ceiling: $7 \mathrm{mg} / \mathrm{m}^{3}$ \\
\hline ACGIH TLV & - & Ceiling: $3 \mathrm{mg} / \mathrm{m}^{3}$ \\
\hline
\end{tabular}

${ }^{*}$ The MDC of hydrochloric acid was $2.7 \mu \mathrm{g} / \mathrm{m}^{3}$ using an average sample volume of $1.13 \mathrm{~m}^{3}$. 


\section{References}

ACGIH [2017]. 2017 TLVs ${ }^{\circledR}$ and BEIs ${ }^{\circledR}$ : threshold limit values for chemical substances and physical agents and biological exposure indices. Cincinnati, OH: American Conference of Governmental Industrial Hygienists.

ATSDR [1999]. Toxicological profile for formaldehyde. Agency for Toxic Substances and Disease Registry, http://www.atsdr.cdc.gov/toxprofiles/tp111.pdf.

ATSDR [2015]. ToxFAQs ${ }^{\text {TM }}$ for formaldehyde. Agency for Toxic Substances and Disease Registry, http://www.atsdr.cdc.gov/toxfaqs/tf.asp?id=219\&tid=39.

Blumenthal I [2001]. Carbon monoxide poisoning. J R Soc Med 94(6):270-272, https://www.ncbi.nlm.nih.gov/pmc/articles/PMC1281520/.

CFR. Code of Federal Regulations. Washington, DC: U.S. Government Printing Office, Office of the Federal Register.

Grassi M, Rezzani C, Biino G, Marinoni A [2003]. Asthma-like symptoms assessment through ECRHS (European Community Respiratory Health Survey) screening questionnaire scoring. J Clin Epidemiol 56(3):238-247, http://dx.doi.org/10.1016/S0895-4356(02)00613-3.

Jaakkola JJK, Knight TL [2008]. The role of exposure to phthalates from polyvinyl chloride products in the development of asthma and allergies: a systematic review and meta-analysis. Environ Health Perspect 116(7):845-853, https://dx.doi.org/10.1289\%2Fehp.10846.

Lavonias EJ [2007]. Carbon monoxide poisoning. In: Shannon MW, Borron SW, Burns MJ, eds. Haddad and Winchester's clinical management of poisoning and overdose, 4th ed. Philadelphia, PA: Saunders Elsevier.

Maloney G [2016]. Carbon monoxide. In: Tintinalli JE, Stapczynski J, Ma O, Yealy DM, Meckler GD, Cline DM, Tintinalli JE, Stapczynski J, Ma O, Yealy DM, Meckler GD, Cline DM eds. Tintinalli's emergency medicine: a comprehensive study guide, 8e. New York: McGraw-Hill, $\underline{\mathrm{http}}$ ://accessemergencymedicine.mhmedical.com/content.aspx?bookid=1658\&Section $\underline{\mathrm{id}=109386458 .}$.

NLM [2010]. Toxnet hazardous substances database: diethyl phthalate CASRN:84-66-2. Bethesda, MD: U.S. National Library of Medicine, National Institutes of Health, Toxnet Toxicology Data Network.

NLM [2015a]. Toxnet hazardous substances database: dimethyl phthalate CASRN:131-11-3. Bethesda, MD: U.S. National Library of Medicine, National Institutes of Health, Toxnet Toxicology Data Network. 
NLM [2015b]. Toxnet hazardous substances database: hydrogen chloride CASRN:7647-01-0. Bethesda, MD: U.S. National Library of Medicine, National Institutes of Health, Toxnet Toxicology Data Network.

NIOSH [1991]. Building air quality - a guide for building owners and facility managers. Cincinnati, OH: U.S. Department of Health and Human Services, Centers for Disease Control and Prevention, National Institute for Occupational Safety and Health. DHHS (NIOSH) Publication No. 91-114, https://www.cdc.gov/niosh/docs/91-114/.

NIOSH [2010]. NIOSH pocket guide to chemical hazards. Cincinnati, OH: U.S. Department of Health and Human Services, Centers for Disease Control and Prevention, National Institute for Occupational Safety and Health, DHHS (NIOSH) Publication No. 2010-168c, http://www.cdc.gov/niosh/npg/.

NIOSH [2017]. NIOSH manual of analytical methods (NMAM). 5th ed. O'Connor PF, Ashley K, eds. Cincinnati, OH: U.S. Department of Health and Human Services, Centers for Disease Control and Prevention, National Institute for Occupational Safety and Health, DHHS (NIOSH) Publication No. 2014-151, http://www.cdc.gov/niosh/nmam.

OSHA [2017]. OSHA sampling and analytical methods. Hendricks W, ed. Salt Lake City, UT: U.S. Department of Labor, Occupational Safety and Health Administration, http://www.osha.gov/dts/sltc/methods/index.html.

Palmer RB, Phillips SD [2007]. Chlorinated hydrocarbons. In: Shannon MW, Borron SW, Burns MJ, eds. Haddad and Winchester's clinical management of poisoning and overdose, 4th ed. Philadelphia, PA: Saunders Elsevier.

Salonen H, Pasanen AL, Lappalainen S, Riuttala H, Tuomi T [2009]. Volatile organic compounds and formaldehyde as explaining factors for sensory irritation in office environments. J Occup Environ Hyg 6(4):239-247, http://dx.doi.org/10.1080/15459620902735892.

Wallingford KM [2009]. Letter from K.M. Wallingford, Division of Surveillance, Hazard Evaluations and Field Studies, to Mr. George R. Betters, Director Central Services Division. U.S. Equal Employment Opportunity Commission, August 12. 
Keywords: North American Industry Classification System 326113 (Unlaminated Plastics Film and Sheet [Except Packaging] Manufacturing), South Dakota, Occupational Asthma, Carbon Monoxide, Phthalates, Hydrogen Chloride, Plastic, Heat Sealing 
This page left intentionally blank 
The Health Hazard Evaluation Program investigates possible health hazards in the workplace under the authority of the Occupational Safety and Health Act of 1970 (29 U.S.C. § 669(a) (6)). The Health Hazard Evaluation Program also provides, upon request, technical assistance to federal, state, and local agencies to investigate occupational health hazards and to prevent occupational disease or injury. Regulations guiding the Program can be found in Title 42, Code of Federal Regulations, Part 85; Requests for Health Hazard Evaluations (42 CFR Part 85).

\section{Disclaimer}

The recommendations in this report are made on the basis of the findings at the workplace evaluated and may not be applicable to other workplaces.

Mention of any company or product in this report does not constitute endorsement by NIOSH.

Citations to Web sites external to NIOSH do not constitute NIOSH endorsement of the sponsoring organizations or their programs or products. NIOSH is not responsible for the content of these Web sites. All Web addresses referenced in this document were accessible as of the publication date.

\section{Acknowledgments}

Analytical Support: Bureau Veritas North America

Desktop Publisher: Shawna Watts

Editor: Ellen Galloway

Industrial Hygiene Field Assistance: Jessica Ramsey, Karl Feldmann

Logistics: Donnie Booher, Kevin Moore

Medical Field Assistance: George Reed Grimes

\section{Availability of Report}

Copies of this report have been sent to the employer and employees at the facility. The state and local health department and the Occupational Safety and Health Administration Regional Office have also received a copy. This report is not copyrighted and may be freely reproduced.

\section{Recommended citation for this report:}

NIOSH [2017]. Evaluation of exposures and symptoms from heat sealing operations at a plastic film assembly facility. By Couch J, Eisenberg J. Cincinnati, OH: U.S. Department of Health and Human Services, Centers for Disease Control and Prevention, National Institute for Occupational Safety and Health, NIOSH Health Hazard Evaluation Report 2014-0111-3280, http://www.cdc.gov/niosh/hhe/reports/ pdfs/2014-0111-3280.pdf. 
Delivering on the Nation's promise:

Safety and health at work for all people through research and prevention

To receive NIOSH documents or more information about occupational safety and health topics, please contact NIOSH:

Telephone: 1-800-CDC-INFO (1-800-232-4636)

TTY: 1-888-232-6348

CDC INFO: www.cdc.gov/info

or visit the NIOSH Web site at www.cdc.gov/niosh

For a monthly update on news at $\mathrm{NIOSH}$, subscribe to $\mathrm{NIOSH}$ eNews by visiting www.cdc.gov/niosh/eNews. 